\title{
Ileal atresia and severe cerebral injury after fetoscopic laser photocoagulation treatment for twin-to-twin transfusion syndrome
}

\author{
Ayşe Anık ${ }^{1 \oplus}$, Abdullah Barış Akcan ${ }^{1 \oplus}$, İrem Çulcuoğlu ${ }^{2 \oplus}$, Ali Onur Erdem ${ }^{3 \oplus}$, \\ Sezen Karaca Özkısacık ${ }^{3 \oplus}$, Münevver Kaynak Türkmen ${ }^{1 \oplus}$ \\ Departments of ${ }^{1}$ Neonatology, ${ }^{2}$ Pediatrics and ${ }^{3}$ Pediatric Surgery, Aydin Adnan Menderes University Faculty of Medicine, Aydin, Turkey.
}

\begin{abstract}
Background. Twin-to-twin transfusion syndrome (TTTS) is a significant cause of perinatal morbidity and mortality. Fetoscopic laser photocoagulation (FLP) is the optimal treatment option for twin-to-twin transfusion syndrome; but can cause central nervous system, extremity and intestinal system injury.

Case. We report the case report of ileal atresia and severe cerebral infarction co-occurrence after fetoscopic laser photocoagulation treatment. It is uncertain as to whether ileal atresia occurred due to ischemia associated with TTTS, the treatment with FLP, or a combination of both.

Conclusions. Cases with prenatal ultrasonographic abnormalities after FLP should have a close assessment to detect bowel complications. Despite many developments in its management, TTTS remains an important risk factor for cerebral injury.
\end{abstract}

Key words: twin-to-twin transfusion syndrome, fetoscopic laser photocoagulation, ileal atresia, cerebral injury.

Twin-to-twin transfusion syndrome (TTTS) is observed in $10-15 \%$ of monochorionic pregnancies and is a significant cause of perinatal morbidity and mortality. The main cause of TTTS is vascular anastomosis in the placenta. If TTTS is not treated, the perinatal mortality rate reaches $80-90 \%{ }^{1}$ Fetoscopic laser photocoagulation (FLP) is the optimal treatment option for TTTS. There are very few cases of central nervous system, extremity, and intestinal system injury that develop after FLP treatment. ${ }^{2}$ This case report presents a neonate with ileal atresia and severe cerebral ischemia that developed after FLP treatment for TTTS.

\section{Case Report}

A 32-year old mother presented with TTTS, Quintero stage I, at 18 weeks of gestation. No

Ayşe Anık

drayseank@yahoo.com

Received 23rd May 2020, accepted 26th November 2020. congenital anomalies were found in either twin by ultrasonography (USG); and FLP was performed at 18 weeks of gestation without any complication. Fetal chromosome analysis showed a 46, XY karyotype. Fetuses were monitored once or twice a week by USG. At the 32 weeks of pregnancy, magnetic resonance imaging (MRI) showed widespread cystic leukoencephalomalacia in the left cerebral hemisphere parenchyma and ascites (free fluid in the abdominal cavity) in the recipient fetus, while the donor fetus was normal (Fig. 1). Follow-up monitoring by USG showed no flow in the middle cerebral artery, which was compatible with MRI findings. At 33 weeks of gestation, a cesarean section was performed for persistent uterine contractions. The donor twin, with a birth weight of $1850 \mathrm{~g}$, with a hemoglobin level of $13.1 \mathrm{~g} / \mathrm{dl}$, was hemodynamically stable and developed mild acute respiratory distress. The follow up of the donor was uneventful, and physical examination of the baby and abdomen and brain MRI were normal. The recipient 


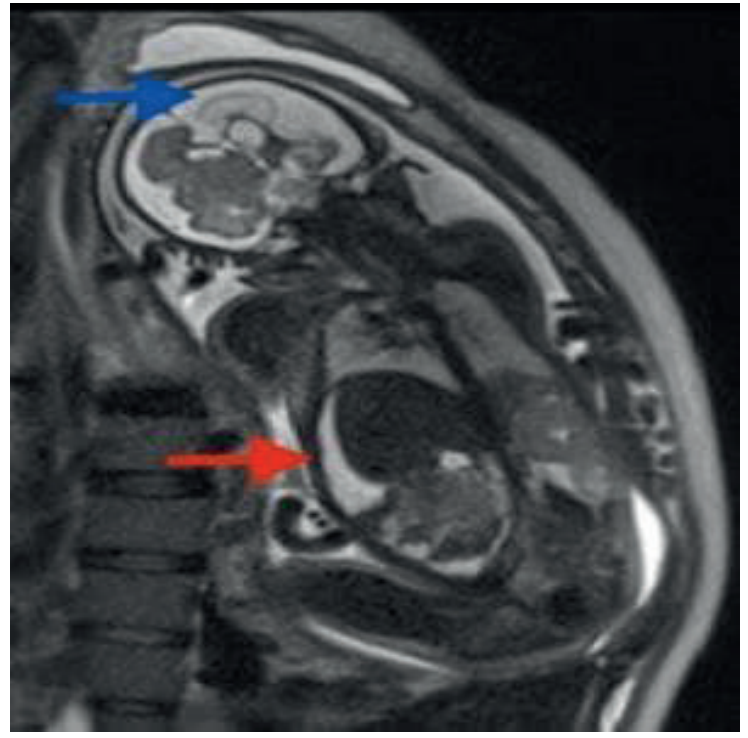

Fig. 1. Prenatal magnetic resonance imaging: Widespread cystic leukoencephalomalacia in left cerebral hemisphere (blue arrow) and ascites (red arrow) in recipient fetus.

twin, with a birth weight of $2250 \mathrm{~g}$, with a hemoglobin level of $16.1 \mathrm{~g} / \mathrm{dl}$, had abdominal distention and exhibited signs and symptoms of intestinal obstruction after 24 hours of birth. Laparotomy was performed on day 2 of life, an atretic segment of ileum that was $30 \mathrm{~cm}$ apart from the ileocecal valve was resected and primary end-to-end anastomosis was performed (Fig. 2). Pathological examination of the specimen revealed abnormal villous configuration, luminal obliteration, narrowing, fibrosis and calcification, consistent with ileal atresia. Cranial MRI showed brain volume loss and periventricular cystic encephalomalacia areas in the left cerebral hemisphere (Fig. 3). Newborn screening for inherited metabolic disorders was normal. The baby was exclusively fed breast milk and discharged at 37 weeks of corrected age. An informed consent was obtained from the parents before the study.

\section{Discussion}

This case report presents the association of ileal atresia and severe neurologic injury observed in the recipient twin in a monochorionic pregnancy with FLP treatment for TTTS.

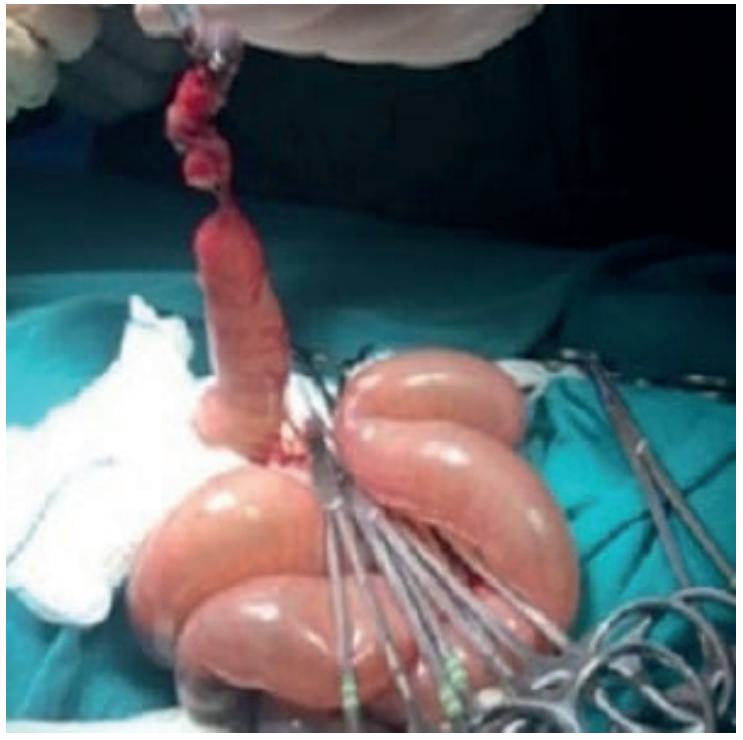

Fig. 2. Surgical image: Ileal atresia.

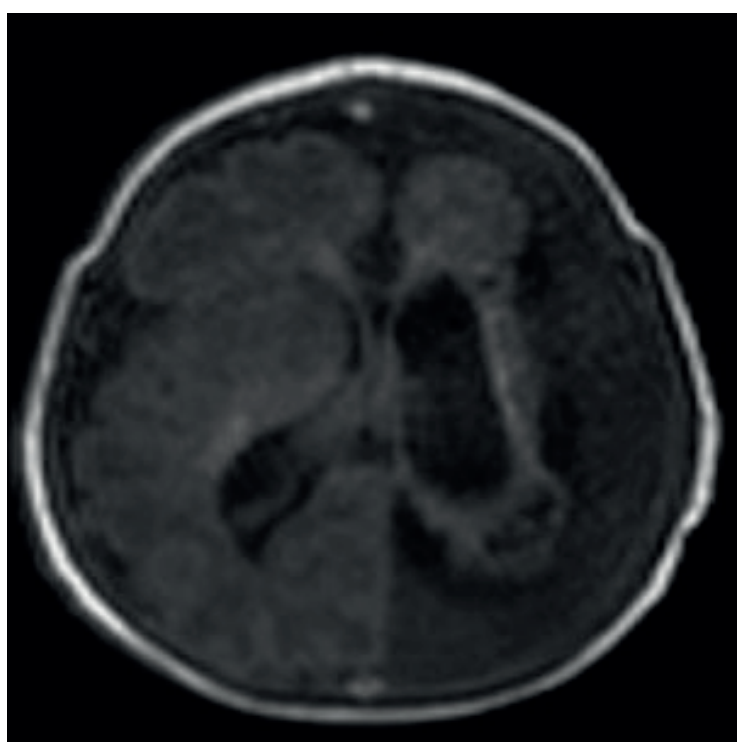

Fig. 3. Postnatal magnetic resonance image: Widespread cystic leukoencephalomalacia, widespread parenchyma loss and compensatory expansion of left lateral ventricle in left cerebral hemisphere.

Small bowel atresia is a rare congenital malformation. Duodenal atresia develops as a result of disrupted rechanneling of the intestine, while jejunoileal atresia is thought to result from a mesenteric vascular accident. ${ }^{3}$ The EUROCAT study reported the prevalence of jejunoileal atresia as 0.7 per 10,000 live births 
among babies from singleton pregnancies with normal karyotype, while the same study reported that 21 of 423 jejunoileal atresia cases were twin cases with unstated chorionic status. ${ }^{3}$ Similarly, Cragan et al. ${ }^{4}$ reported the increased incidence of jejunoileal atresia in monozygotic twin pregnancies.

Several cases of congenital intestinal atresia or ileal perforation after FLP have been reported (Table I). In monochorionic twins, it is thought that mesenteric ischemia linked to hypoperfusion and hyperviscosity secondarily to vascular anastomosis or thromboembolisms after FLP treatment may play a role in small intestine atresia. A literature search revealed 16 cases who developed jejunoileal atresia/ perforation after FLP treatment, with our patient being the $17^{\text {th }}$ case. Jejunoileal atresia was more common in the recipients than those of donors (Table I). Bowel complications can be seen in both fetuses by different etiologies. While, polycythemia and hyperviscosity due to transfusion may cause vascular accidents in the recipient twin; anemia in the donor twin may cause persistent hypoperfusion of the intestine, and the resulting hypoxemic damage may lead to bowel necrosis and perforation. Moreover, thrombosis of placental vessels could cause intestinal ischemia in both the recipient and the donor twin. Schnater et al. ${ }^{5}$ speculated that thrombo-emboli may be induced by the laser coagulation of the placental vessels. Of the cases given in Table I, isolated fetal ascites was detected in 4 cases, as in our patient. This case report is important as it should be kept in mind that isolated fetal ascites noted on ultrasound after FLP treatment for TTTS is not necessarily secondary to fetal anemia but may be secondary to in utero bowel perforation. Due to the small number of cases available currently, more detailed studies are needed to reveal the exact underlying pathologies of bowel complications after FLP treatment.

To the best of our knowledge, this is the first case with co-occurrence of ileal atresia and severe cerebral infarction after FLP treatment.

Table I. Type of bowel problems associated with twin-to-twin transfusion syndrome after fetoscopic laser photocoagulation.

\begin{tabular}{|c|c|c|c|c|}
\hline $\begin{array}{l}\text { Case } \\
\text { No. }\end{array}$ & Lesion & $\begin{array}{l}\text { Affected } \\
\text { twin }\end{array}$ & Associated anomalies & Authors \\
\hline 1 & Ileal atresia & $\mathrm{R}$ & No & Arul et al. ${ }^{13}$ \\
\hline 2 & Ileal atresia & $\mathrm{R}$ & No & \\
\hline 3 & Ileal atresia & $\mathrm{R}$ & No & Schnater et al. ${ }^{5}$ \\
\hline 4 & Ileal atresia & $\mathrm{R}$ & No & Morikawa et al. ${ }^{14}$ \\
\hline *5,6 & $\begin{array}{l}\text { D: Sigmoid perforation, } \\
\text { R: Ileocecal perforation }\end{array}$ & $\mathrm{D}, \mathrm{R}$ & No & Detlefsen et al. ${ }^{15}$ \\
\hline 7 & Ileal atresia and perforation & $\mathrm{R}$ & Pulmonary stenosis & Saura et al. ${ }^{16}$ \\
\hline 8 & Jejunal atresia & $\mathrm{D}$ & No & \\
\hline$* * 9,10$ & $\begin{array}{l}\text { D: Transverse colon perforation, } \\
\text { R: Jejunal perforation }\end{array}$ & $\mathrm{D}, \mathrm{R}$ & No & Marcellin et al. ${ }^{17}$ \\
\hline 11 & Jejunal atresia, sigmoid perforation & $\mathrm{D}$ & No & Sanchez-Galan et al. ${ }^{18}$ \\
\hline 12 & Ileal atresia & $\mathrm{R}$ & No & \\
\hline 13 & Ileal atresia & $\mathrm{D}$ & No & \\
\hline 14 & Caecal perforation & $\mathrm{R}$ & No & \\
\hline 15 & Ileal atresia and perforation & $\mathrm{D}$ & No & Piek et al. ${ }^{19}$ \\
\hline 16 & Jejunal atresia and perforation & $\mathrm{R}$ & No & Tan et al. ${ }^{20}$ \\
\hline 17 & Ileal atresia and perforation & $\mathrm{R}$ & Brain injury & Current case \\
\hline
\end{tabular}

$\mathrm{D}$, donor; $\mathrm{R}$, recipient. ${ }^{*}$ Case 5 is donor and Case 6 is recipient in the same pregnancy, ${ }^{* *}$ Case 9 is donor and Case 10 is recipient in the same pregnancy 
The cause of cerebral injury in TTTS cases is still not clearly defined. The risk factors for neurological morbidity have been reported as high Quintero stage, low birth weight, low gestational age at birth, and advanced gestational age at laser surgery ${ }^{6}$. Injury patterns are classified as hemorrhagic (intraventricular hemorrhage, periventricular hemorrhagic infarcts) or ischemic white matter injury (periventricular leukomalacia) according to USG. ${ }^{7}$ Both forms of injury may develop in the antenatal period linked to disrupted cerebral blood flow. ${ }^{8}$ In TTTS, compromised cerebral perfusion and ischemic injury of the central nervous system may occur due to vascular anastomoses, independent of FLP treatment. ${ }^{9}$ There are some studies reporting lower rates of neurologic complications and higher survival rates after FLP treatment. Rossi et al. ${ }^{10}$ reported less mortality and fewer neurologic sequelae in fetuses that were treated with laser photocoagulation. Miralles-Gutiérrez et al. ${ }^{11}$ reported the global mean rate of neurological injury in twins treated with FLP as $14.07 \%$ and emphasized that the rate was higher than the results found in dichorionic twins but lower than the results found in twins treated with serial amnio-reductions or conservative management. Lopriore et al. ${ }^{7}$ reported the incidence of antenatally acquired severe cerebral lesions in the TTTS group as $10 \%(8 / 84)$ and $2 \%(2 / 108)$ in the non-TTTS group (OR 5.58, 95\% CI 1.05 to $39.21, \mathrm{p}=.02$ ). They emphasized the need for fetal imaging before and after the intervention to determine the effect of FLP on cerebral injury. ${ }^{7}$ Conversely, a study conducted by Weisz et al. ${ }^{12}$ showed ischemic changes in white matter on fetal diffusion-weighted magnetic resonance imaging taken 24-96 hours after FLP treatment. They proposed these changes may be associated with FLP treatment. As a result, it is unknown whether cerebral injury develops before, during or after FLP treatment.

In conclusion, this case report emphasizes that intestinal complications should be kept in mind in TTTS after FLP therapy, especially in case of isolated fetal ascites. Despite many developments in its management, TTTS remains an important risk factor for cerebral injury.

\section{Author contribution}

The authors confirm contribution to the paper as follows: case report conception and design: AA, ABA, MKT; data collection: AA, İÇ; draft case report preparation: $\mathrm{AA}, \mathrm{AOE}, \mathrm{SKÖ}, \mathrm{ABA}$, MKT. All authors reviewed the results and approved the final version of the case report.

\section{Conflict of interest}

The authors declare no conflict of interest.

\section{REFERENCES}

1. Berghella V, Kaufmann M. Natural history of twintwin transfusion syndrome. J Reprod Med 2001; 46: 480-484.

2. Slaghekke F, Lopriore E, Lewi L, et al. Fetoscopic laser coagulation of the vascular equator versus selective coagulation for twin-to-twin transfusion syndrome: an open-label randomised controlled trial. Lancet 2014; 383: 2144-2151.

3. Best KE, Tennant PW, Addor MC, et al. Epidemiology of small intestinal atresia in Europe: a register based study. Arch Dis Child Fetal Neonatal Ed 2012; 97: F353-F358.

4. Cragan JD, Martin ML, Waters GD, Khoury MJ. Increased risk of small intestinal atresia among twins in the United States. Arch Pediatr Adolesc Med 1994; 148: 733-739.

5. Schnater JM, van Zalen-Sprock RM, Schaap AH, Festen S, Aronson DC. Ileal atresia and thromboembolic liver calcifications diagnosed after treatment with intrauterine laser coagulation therapy for twinto-twin transfusion syndrome: report of 2 cases. J Pediatr Surg 2005; 40: 875-876.

6. Lopriore E, Ortibus E, Acosta-Rojas R, et al. Risk factors for neurodevelopment impairment in twintwin transfusion syndrome treated with fetoscopic laser surgery. Obstet Gynecol 2009; 113(2 Pt 1): 361-366.

7. Lopriore E, van Wezel-Meijler G, Middeldorp JM, Sueters M, Vandenbussche FP, Walther FJ. Incidence, origin, and character of cerebral injury in twin-totwin transfusion syndrome treated with fetoscopic laser surgery. Am J Obstet Gynecol 2006; 194: 12151220. 
8. Volpe JJ. Intracranial hemorrhage: germinal matrixintraventricular hemorrhage of the premature infant. In: Volpe JJ (ed). Neurology of the Newborn (5th ed) Chapter 11. Philadelphia: Saunders, 2008: 517-590.

9. Banek CS, Hecher K, Hackeloer BJ, Bartmann P. Long-term neurodevelopmental outcome after intrauterine laser treatment for severe twin-twin transfusion syndrome. Am J Obstet Gynecol 2003; 188: 876-880.

10. Rossi AC, D'Addario V. Laser therapy and serial amnioreduction as treatment for twin-twin transfusion syndrome: a metaanalysis and review of literature. Am J Obstet Gynecol 2008; 198: 147-152.

11. Miralles-Gutiérrez A, Narbona-Arias I, GonzálezMesa E. Neurological complications after therapy for fetal-fetal transfusion syndrome: a systematic review of the outcomes at 24 months. J Perinat Med 2018; 46: 991-997.

12. Weisz B, Hoffmann C, Ben-Baruch S, et al. Early detection by diffusion-weighted sequence magnetic resonance imaging of severe brain lesions after fetoscopic laser coagulation for twin-twin transfusion syndrome. Ultrasound Obstet Gynecol 2014; 44: 44-49.

13. Arul GS, Carroll S, Kyle PM, Soothill PW, Spicer RD. Intestinal complications associated with twintwin transfusion syndrome after antenatal laser treatment: report of two cases. J Pediatr Surg 2001; 36: 301-302.
14. Morikawa M, Sago H, Yamada T, et al. Ileal atresia after fetoscopic laser photocoagulation for twin-totwin transfusion syndrome--a case report. Prenat Diagn 2008; 28: 1072-1074.

15. Detlefsen B, Boemers TM, Schimke C. Necrotizing enterocolitis in premature twins with twin-to-twin transfusion syndrome. Eur J Pediatr Surg 2008; 18: 50-52.

16. Saura L, Muñoz ME, Castañón M, et al. Intestinal complications after antenatal fetoscopic laser ablation in twin-to-twin transfusion syndrome. J Pediatr Surg 2010; 45: E5-E8.

17. Marcellin L, Quintana A, Essaoui M, et al. Meconium peritonitis in both fetuses with early twin-to-twin transfusion syndrome. Twin Res Hum Genet 2012; 15: 527-531.

18. Sánchez-Galán A, Encinas JL, Antolín E, et al. Intestinal complications in twin-to-twin transfusion syndrome (TTTS) treated by laser coagulation (LC). Cir Pediatr 2017; 30: 33-38.

19. Piek MW, Oepkes D, Lopriore E, Hulsker CC. Ileal blowout due to ileal atresia in a donor with twin-totwin transfusion after fetoscopic laser surgery. Ann Pediatr Surg 2018; 14: 42-43.

20. Tan LN, Cheung KW, Philip I, Ong S, Kilby MD. Isolated ascites in a monochorionic twin after fetoscopic laser ablation is not necessarily secondary to recurrence or anaemia: bowel complications in twin-to-twin transfusion syndrome after fetoscopic laser ablation. Fetal Diagn Ther 2019; 45: 285-294. 